The prevalence of contemporary fundamentalism may have coloured Mayr's attitudes, but they rob him of a good deal of historical sympathy and cause him to undervalue a lot of historical scholarship on the subtle interplay between cultural beliefs and scientific discoveries. Mayr himself seems uncertain about this issue, for while granting the "power of ideologies" in scientific thinking (pp.834-835), he elsewhere questions whether any connections exist "between the scientific advances and the general intellectual and social milieu" (p.124).

What is certain, however, are the connections between Mayr's scientific beliefs and the kind of history he writes. He is suspicious of mathematics in biology, and has little time for biometricians or the more recent computer-based taxonomists. He dislikes contemporary theories of macroevolution, so his former student Stephen Jay Gould is conspicuously absent from his long list of acknowledgments and virtually absent from his text. In fact, it could be argued that Mayr's book is not history in the conventional sense, but what Simpson's review playfully called "autobiology" and what John Henry Newman, custodian of a faith for which Mayr has no time, might have dubbed an Apologia pro vita sua.

W.F. Bynum is at the Wellcome Institute for the History of Medicine, 183 Euston Road, London $N W 12 B P, U K$.

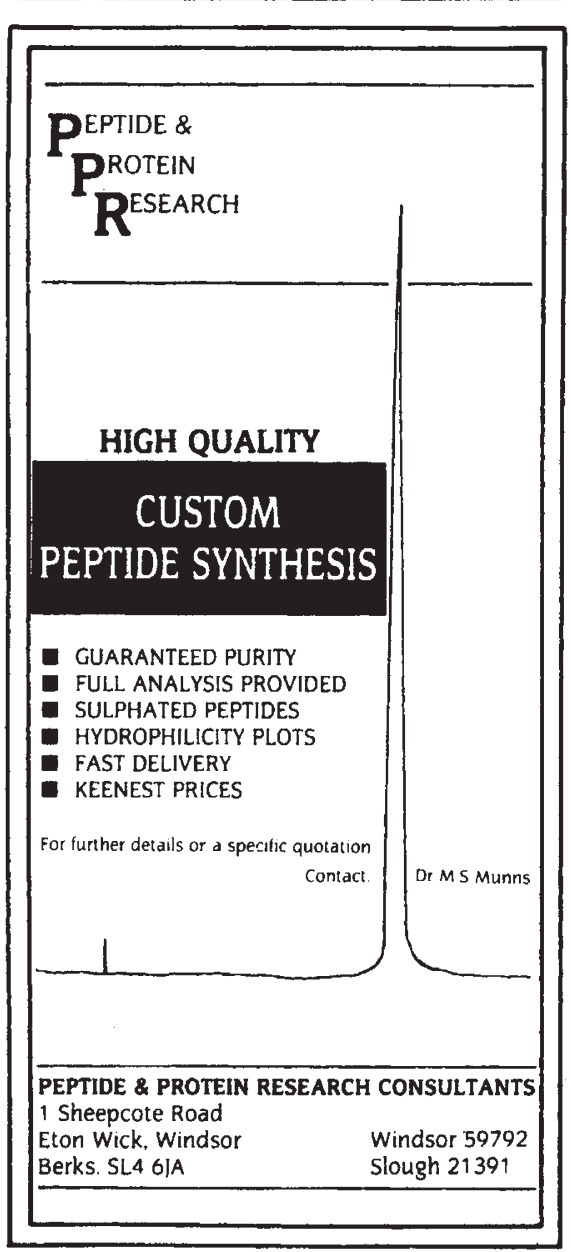

Reader Service No.21

\section{Odd astronomers and other curiosities}

\section{David W. Hughes}

The Astronomical Scrapbook: Skywatchers, Pioneers, and Seekers in Astronomy. By Joseph Ashbrook. Cambridge University Press/Sky Publishing: 1985. Pp.468. £12.95, \$19.95.

SCRAPBOOKS, stamped with the collectors' idiosyncracies, can hardly fail to be fascinating. From the very meaning of Scrapbook in the title of a book, you know that you are going to be led down a series of byways, that the items will be easily digestible, and that you can happily dive in at random, enjoy an intellectual snack, and then put the collection aside for a future treat. And you know that you will be taken by surprise.

Joseph Ashbrook (1918-1980) joined the staff of Sky and Telescope, America's foremost astronomical magazine, in 1953. Every other month for 23 years he wrote a column entitled "Astronomical Scrapbook". He was intrigued by the human aspect of astronomy and revelled in accumulating details about obscure, overlooked astronomers whose fleeting fame had long since been forgotten. He constantly reminded his readers that the history of astronomy is not a tale of steady, relentless progress, but one that reflects life, where mistakes, failures and frailty are all too common.

Ninety-one of Ashbrook's best articles have been assembled into this book, sub-

divided into seven sections: "Star Crossed Lives" (a collection of biographical essays); "Telescopes and Techniques"; "Phenomena of the Earth, Moon and Planets"; "Studies and Students of the Moon"; "Planets and other Solar System Objects"; "Stars and Stellar Systems"; and, finally, "Star Atlases".

We read of August Sonntag ("a tantalizing figure, dimly glimpsed") and Smyth's Celestial Cycle ("a cloudy-night solace to the amateur observer"); of immense telescopes which were "only about as useful as the enormous spectacles which were suspended over the doors of opticians"; and of Dr Peate, a clergyman who figured mirrors, none of which ever seemed to have been put to serious use ("by presenting them to colleges that could not find funds to build and staff observatories, he effectively buried them"). What is an Angosiade? What did Dawes' dog Dash do? How long does it take to estimate the colour of a star? Answers to all these questions are here, and to many more besides.

A typical Ashbrook line is "The story involves an Austrian Naval officer, a Massachusetts clergyman, a German school teacher, and a group of mathematical astronomers at the University of Cincinnati". But underlying each story line is Ashbrook's scholarship, exactitude and love of detail. The book kindles a desire to learn more, a desire which can be satiated thanks to an extensive reference section. This is a gem of an anthology which can be savoured time and again.

David W. Hughes is Senior Lecturer in Astro. nomy and Physics in the Department of Physics, University of Sheffield, Sheffield S3 7RH, UK.

\section{Pictures of the past}

\section{W.S. McKerrow}

Elsevier's Invertebrate Fossils Chart. By P. Lof. Elsevier:1985. 10 copies Dfl.235, $\$ 87$, with reduced rates for larger orders.

ELSEVIER's latest chart, for which you first require a large $(95 \times 135 \mathrm{~cm})$, clear space of wall, shows coloured photographs of over 150 fossils, arranged taxonomically. There are notes explaining the classification of the common invertebrate phyla, their classes and orders, and annotated diagrams illustrating some of the more usual morphological terms. Smaller graphs indicate the stratigraphic ranges of the commoner classes and orders.

The photographs are taken mostly from A.E. Richter's book, Fossilien zum Sameln, published by Franckh'sche Verlaghandlung in 1980 . The fossils are predominantly from Germany, France, Bohemia and Scandinavia, with 20 or so from the United States and a sprinkling from other countries.
The chart will form a pleasing decoration to a student's study, but not everyone will find the price as attractive; several introductory textbooks cost only about double the amount and provide much fuller descriptions and illustrations. Moreover, a real beginner may be confused by so many names of orders, and will certainly find much of the terminology perplexing. Despite the claim that the chart will provide students of geology with all the information they need about invertebrate fossils, I would still recommend a good introductory text which indicates fully how and where these animals lived, and which uses a minimum of technical terms. For myself, I will continue to prefer to use real fossils as examples in teaching.

Still, the chart is useful ancillary material, and if a wall chart is what you want this one is clear, accurate and colourful. To some extent, the photographs speak for themselves and will certainly help the student and the amateur collector to recognize examples of the major groups of invertebrate fossils.

W.S. McKerrow is a Lecturer in the Department of Earth Sciences, University of Oxford, Parks Road, Oxford OXI 3PR, UK. 